\title{
BRIEF \\ Critical Elements of a School Report to Parents on Body Mass Index
}

\author{
Hannah R. Thompson, PhD, MPH; Jennifer K. Linchey, MPH; \\ Kristine A. Madsen, MD, MPH
}

Suggested citation for this article: Thompson HR, Linchey JK, Madsen KA. Critical Elements of a School Report to Parents on Body Mass Index. Prev Chronic Dis 2015;12:150165. DOI: http:// dx.doi.org/10.5888/pcd12.150165.

\section{PEER REVIEWED}

\section{Abstract}

School-based body mass index (BMI) screening and reporting could have a positive impact on student health, but best practices for writing a report are unknown. Building on previous qualitative work, 8 focus groups were conducted with a diverse group of California parents $(n=79)$ to elicit feedback on report content and design. Results indicate that parents want a visually appealing, picture-heavy report that clearly defines BMI, avoids stigmatizing language, and includes recommendations for appropriate actions whole families can take. Next steps involve using the final report in a statewide, randomized trial to determine the effectiveness of school-based BMI screening and reporting in reducing childhood obesity.

\section{Objective}

The Institute of Medicine recommends that schools implement BMI screening and reporting practices to combat childhood obesity (1). As of 2010, 20 states, including California, required BMI screening, 9 of which mandated sending reports to parents (2). Current reports are difficult to understand, however, especially for parents with low literacy skills (3). Furthermore, terminology for describing children with a BMI in or higher than the 95th percentile is inconsistent and has provoked controversy, particularly the use of the word "obese." Despite prior formative research with parents on BMI report design, best practices for reporting remain unknown. This study sought to identify appropriate content for BMI reports, in preparation for a large randomized trial of school-based BMI screening and reporting.

\section{Methods}

Eight focus groups (60-90 minutes) were held in schools with 79 parents $(97 \%$ female) who identified as Latino, non-Hispanic white, African American, or Asian American; 53\% had no more than a high school diploma. Focus groups were conducted for each racial/ethnic category, proportional to the makeup of California public schools: 4 Latino (2 English-speaking, 2 Spanishspeaking); 2 non-Hispanic white; 1 African American; and 1 Asian American. Parents were recruited via school contacts and listservs from 9 low-income elementary and middle schools (prevalence of overweight: $56 \%$; free or reduced-cost meal eligibility: $79 \%$ ) across 4 Northern California school districts in March through July 2014. One-third of parents reported being told their child had a high BMI.

A semistructured script was used to elicit opinions on 1) preferred language around weight terminology (including "obese" and "overweight," and prompts for other possible terms); 2) inclusion of BMI (vs height and weight alone); 3 ) recommendations to promote positive behavior change; and 4) report formatting. Two trained moderators facilitated audio-recorded groups (one led groups in English, one in Spanish) with assistance from a trained co-moderator. The University of California Berkeley Committee for the Protection of Human Subjects approved this study; informed consent was not obtained.

Audio files were transcribed verbatim, and Spanish transcriptions were translated into English. Two researchers coded all transcripts using a codebook developed through a thematic analysis approach (based on predetermined theories about BMI reporting) that allowed for emergent themes (4). Coding and content analysis were executed and organized using NVivo 10.1 software (QSR International). 


\section{Results}

An average of 9 parents (range, 4-13) participated per group. Parents had mixed familiarity with BMI, but preferred that it be included (rather than providing height and weight alone) and clearly defined. Parents overwhelmingly wanted a visual representation of BMI, with BMI ranges for each weight category to understand where their child fell.

Parents preferred "at-risk for overweight" and "overweight" to "overweight" and "obese" when describing students in the $\geq 85$ th through the $>95$ th and $\geq 95$ th percentiles for BMI, respectively. Parents, particularly African American and Latino parents, were opposed to the term "obese," describing it as "off-putting," "ugly," "derogatory," and "traumatizing" to children. Parents liked "atrisk for overweight" because it "implies that something can be changed." Parents also preferred "healthy weight" over "normal weight" because "normal" felt vague and unclear.

Parents wanted the report to include recommendations for possible actions to improve their child's health, especially those relevant for the entire family. Parents were generally familiar with advice to reduce consumption of sugar-sweetened beverages, decrease portion sizes, and limit screen time, but were less familiar with the recommendation for 60 minutes of daily physical activity and wanted that recommendation prominently displayed. When asked to choose, parents preferred the addition of the Healthy Plate Model (5) versus instructions on reading a nutrition label because it is "easier to understand than a nutrition label."

Parents preferred a short, concise report. Many parents described being visual learners and wanted pictures included: "I think for people who are visual, [pictures are] what draws your eye first. Then you see your child's name, and you see them in the overweight category, and then you think, 'I'd better read this letter."' Several parents suggested using stoplight colors (green, yellow, red) to represent the increasing health risks with each BMI category, as well as an arrow to point to exactly where their child falls on the BMI spectrum. Feedback was used to create a single BMI report (Figures 1 and 2).

\begin{abstract}
Your daughter, Alessandra Rodriguez, was measured at school in March, 2015. Alessandra was 4 feet 9 inches tall and weighed 120 pounds. Alessandra's body mass index (BMI) was 29.0 .

BMI is a ratio of a child's weight to height. Doctors use BMI to see if a child's weight might be putting him or her at risk for health problems. The colored bar below shows BMI ranges for 10-year-old girls. The arrow points to Alessandra's BMI, which places her in the overweight range.
\end{abstract}

\begin{tabular}{|c|c|c|c|}
\hline & & \multicolumn{2}{|c|}{ Alessandra's BMI: 29.0} \\
\hline $\begin{array}{c}\text { BMI } \\
11.0-14.9\end{array}$ & BMI 15.0 - 19.9 & BMI $20.0-22.9$ & BMI $23.0-34.9$ \\
\hline
\end{tabular}

Why does this matter?

Studies have shown that many overweight children already have high blood pressure, high cholesterol, or early signs of diabetes. Also, overweight children are more likely to become obese as adults, which can lead to serious health problems. If you have any questions or concerns about Alessandra's BMI, please share this letter with her doctor. What can you do?
The good news is that even small changes can make a big difference in your
child's health.

Turn the page to see what you can do to keep your family healthy. You can also visit www.choosemyplate.gov for more tips and resources. All children, no matter what their weight, should be physically active and eat a healthy diet.

Figure 1. BMI Report (front side of the report)

\footnotetext{
The opinions expressed by authors contributing to this journal do not necessarily reflect the opinions of the U.S. Department of Health and Human Services, the Public Health Service, the Centers for Disease Control and Prevention, or the authors' affiliated institutions.
} 


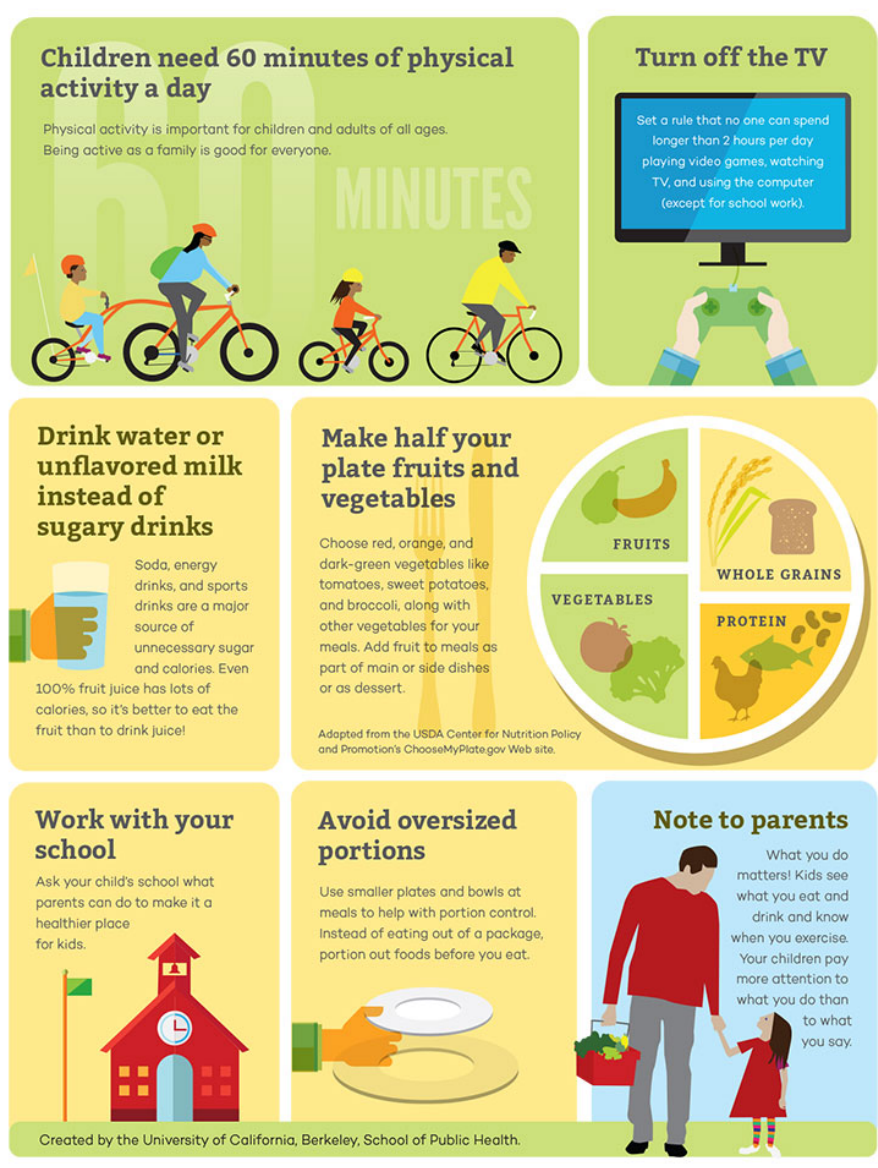

Figure 2. BMI Report (back side of the report).

\section{Discussion}

Building on previous qualitative work (6-8), this study's feedback from diverse parents led to the development of a new BMI report format. The report reflects parents' belief that BMI is a more meaningful indicator of weight status than height and weight alone; a simple and clear definition of BMI and interpretable results need to be included; and recommendations should be targeted to the whole family.

Previous formative work $(7,9)$ similarly demonstrated that parents are uncomfortable with the word "obese." Negative reactions to Massachusetts' recently implemented BMI report (10) may stem, in part, from the report's use of the term. Although using "overweight" instead of "obese" is inconsistent with current CDC terminology, the stigma associated with "obese" may so alienate parents that they disregard the report, outweighing potential termino- logy confusion. CDC itself cites the need to "provide all parents with a clear and respectful explanation of the BMI results" as a BMI measurement program safeguard (11). To assess the potential for unintended consequences related to terminology confusion, we will conduct interviews with parents who receive the BMI report.

On the basis of parents' feedback and research indicating that pictures help convey key messages to low literacy populations (12), we developed an infographic for the recommended actions. Although prior reports used pictorial representations of children's weight status (8), previous qualitative work did not address the visual representation of recommendations. The Massachusetts report included pictures (along with heavy text) on physical activity and nutrition tip sheets. The infographic approach allowed us to collapse information into a single page (front and back) that may be more affordable for schools to implement.

Given the widespread use of BMI reporting in schools (2), more evidence on the impact of such reports is critical. The report based on our study may not effectively reduce obesity; however, it will form the basis for a large randomized trial of BMI screening and reporting as a means of reducing pediatric obesity. Results of that study could have important policy implications.

\section{Acknowledgments}

This research was funded by the National Institutes of Health's National Heart, Lung, and Blood Institute, grant no. R01HL120666-01. We thank Nayeli Cerpas Bernal for leading the Spanish-speaking groups, Christina Becker for providing childcare, the teachers/administrators who helped organize the groups, and all of the parents for their time and thoughtful participation.

\section{Author Information}

Corresponding Author: Hannah R. Thompson, PhD, MPH, University of California, Berkeley School of Public Health, 2115 Milvia St, \#3, Berkeley, CA 94704. Telephone: 510-642-1263. Email: ThompsonH@Berkeley.edu.

Author Affiliations: Jennifer K. Linchey, Kristine A. Madsen, University of California, Berkeley School of Public Health, Berkeley, California. 


\section{References}

1. Institute of Medicine of the National Academies. Preventing childhood obesity. Health in the balance [executive summary]. Washington (DC): The National Academies Press; 2004.

2. Linchey J, Madsen KA. State requirements and recommendations for school-based screenings for body mass index or body composition, 2010. Prev Chronic Dis 2011; 8(5):A101.

3. Madsen KA, Linchey J. School-based BMI and body composition screening and parent notification in California: methods and messages. J Sch Health 2012;82(6):294-300.

4. Fereday J, Muir-Cochrane E. Demonstrating rigor using thematic analysis: a hybrid approach of inductive and deductive coding and theme development. Int J Qual Methods 2006;5(1):80-92.

5. United States Department of Agriculture. Choose My Plate. http://www.choosemyplate.gov. Accessed February 22, 2015.

6. Kubik MY, Story M, Rieland G. Developing school-based BMI screening and parent notification programs: findings from focus groups with parents of elementary school students. Health Educ Behav 2007;34(4):622-33.

7. Moyer LJ, Carbone ET, Anliker JA, Goff SL. The Massachusetts BMI letter: a qualitative study of responses from parents of obese children. Patient Educ Couns 2014; 94(2):210-7.

8. Thompson JW, Card-Higginson P. Arkansas' experience: statewide surveillance and parental information on the child obesity epidemic. Pediatrics 2009;124(Suppl 1):S73-82.

9. Puhl RM, Peterson JL, Luedicke J. Parental perceptions of weight terminology that providers use with youth. Pediatrics 2011;128(4):e786-93.

10. Bidwell A. Massachusetts schools to stop sending "fat letters." US News World Rep 2013;(October 17). http:// www.usnews.com/news/articles/2013/10/17/massachusettsschools-to-stop-sending-fat-letters. Accessed February 20, 2015.

11. Centers for Disease Control and Prevention. Body mass index (BMI) measurement in schools. http://www.cdc.gov/ healthyyouth/obesity/BMI/BMI_measurement_schools.htm. Accessed April 24, 2015.

12. Centers for Disease Control and Prevention, Strategic and Proactive Communication Branch. Simply put: a guide for creating easy-to-understand materials. Third edition. Atlanta (GA); 2009.

\footnotetext{
The opinions expressed by authors contributing to this journal do not necessarily reflect the opinions of the U.S. Department of Health and Human Services, the Public Health Service, the Centers for Disease Control and Prevention, or the authors' affiliated institutions.
} 